\title{
CREATING CONDITIONS FOR WORKING COLLABORATIVELY IN DISCIPLINE-BASED WRITING CENTRES AT A SOUTH AFRICAN UNIVERSITY
}

\author{
Dr Laura Dison \& Ms Jean Moore \\ University of the Witwatersrand
}

Students' academic literacy practices frequently do not prepare them for, or articulate with, the ways of thinking and practising within their chosen academic disciplines (Boughey, 2010; Clarence, 2010; Wingate \& Tribble, 2012). There has been much debate about who should be responsible for responding to this 'articulation gap' (Bitzer, 2009) and how this should be done. In this paper, we posit the importance of working with students in the disciplines and draw on Lillis and Scott's (2007) notion of transformative writing spaces to engage critically with disciplinary culture, norms and practices. We critique 'remedial' approaches to tertiary writing development that treat the articulation gap as a skills deficit that can be overcome by teaching a set of requisite academic literacy skills. We also suggest that increased collaboration between writing centres and discipline-based academic staff has helped to shift the deficit conception to more socially constructed approaches to writing development. We explore conditions in two discipline-specific writing centres that show how writing can be used as a way of engaging all students with core course concepts and in which writing development has been embedded within mainstream, substantive modules in order to facilitate epistemological access (Morrow, 2007) to both disciplinary content and writing in the discourse.

Keywords: writing centres, writing in the disciplines, transformation of higher education, academic literacies, epistemological access, writing consultants, assessment for learning, collaborative pedagogy

\section{INTRODUCTION AND CONTEXT}

In South Africa, the National Benchmark Test has shown that less than a third of first-year university students arrive at university with the required academic literacies to succeed (Joseph, 2016). Several studies (Adam, Backhouse, Baloyi \& Barnes, 2010; Cross, Shalem, Backhouse \& Adam, 2009; Scott, Yeld \& Hendry, 2007) have identified a range of academic, social and material challenges that students encounter at university. Although this reflects the apartheid legacy in terms of race and socioeconomic status, it is also increasingly accepted in South Africa and other contexts - that most students, regardless of their educational or linguistic background, require assistance in acquiring academic literacies at university (Hathaway, 2015). Students entering a system of higher education for the first time need help and support with the transition into unfamiliar academic discourses.

However, deficit approaches to literacy development that label students as in need of 'skills development' are incompatible with the imperative for the transformation of higher education. 
Such 'skills' approaches may perpetuate the notion of the 'decontextualised learner' who is 'separated from her culture, history and language' (Boughey \& McKenna, 2016: 6), exacerbating students' sense of alienation. Boughey and McKenna (2016: 1) point out that, despite a widespread awareness among universities of socio-literacy approaches, such as the academic literacies approach, deficit conceptions of students remain dominant in South Africa. Moreover, they argue that critical socio-literacy ideas 'have often been misappropriated in ways that draw on critical social terminology to offer autonomous, decontextualised student interventions' (Boughey \& McKenna, 2016: 1).

Mann (2001: 7) focuses on the multiple ways in which students experience alienation or are alienated from the content of their studies, the process of learning or from their fellow students, their 'teacher' and the institution itself. There are a number of institutional factors, such as dominant teaching approaches, everyday relationships, curricula, and normal university rules and processes, that function to either engage students or exclude them, thereby leaving historical inequalities unchallenged. Morrell (2016) observes that demands for decolonisation and transformation have not sufficiently explored teaching or pedagogy. Similarly, Mbembe (2016) argues that 'pedagogies of presence' are a necessary part of decolonising the university, so that it facilitates a sense of ownership of tertiary education as a public good. This resonates with our position that generic 'skills' approaches to academic writing development that position students as being the problem and 'at risk' - no matter how well-intentioned - contribute to students' sense of alienation and exclusion that underlies the demand for transformation in higher education. Clarence (2018: 212) sums up this tension: although the field of academic development has moved away from 'deficit discourses', 'quick fix' solutions continue to predominate in the academy.

It is clear that these 'bolt-on' attempts at language and writing remediation have extremely limited impact. Wingate (2011: 66) supports the view that teaching 'study skills' as an additional skill is ineffective, and argues that explicit teaching of academic literacies should be done within disciplinary contexts, by disciplinary experts. MacVaugh, Jones and Auty (2014: 757) offer three convincing arguments in favour of intra-disciplinary literacies development. Firstly, they argue that skills do not automatically transfer from the standalone course to other academic contexts. Secondly, they acknowledge that many learners are assessment-driven, and so 'unless skills are taught in a way that is central to the curriculum and valued through assessment practices, they will not be taken seriously by learners'. The third factor is that (MacVaugh et al., 2014: 757):

academic skills often appear to exist in relation to content knowledge; so, for example, writing an argument is done using a particular body of knowledge and the accompanying conventions. There is a considerable body of evidence - both empirical and theoretical - suggesting that academic skills are part of disciplinary knowledge rather than isolated from it.

However, although there are clear advantages to engaging with academic writing development within the disciplines (Mitchell \& Evison, 2006: 74), this approach remains fairly unusual, mainly due to resource and institutional constraints (Hathaway, 2015: 511).

Jacobs' (2007) notion of 'collaborative pedagogy' offers a local, practical and pedagogically persuasive bridge between 'skills' and 'disciplinary' approaches to academic literacy development. She argues that discipline-specific academic literacies are not always best taught by disciplinary specialists, as their knowledge is so tacit that they may struggle to teach

Per Linguam 2019 35(1):1-14

http://dx.doi.org/10.5785/35-1-851 
this knowledge explicitly and may not prioritise the teaching of writing to engage students with disciplinary concepts. Rather, she proposes 'insider-outsider' collaborations between disciplinary and academic literacies specialists. In this paper, we extend Jacobs' notion of collaborative pedagogy to writing development within the disciplines. This echoes Hutchings' (2006) evaluation of writing centre work at the University of Cape Town more than 12 years ago, in which she strongly advocates for a more discipline-embedded approach to writing development. It also reflects a shift in recent literature: away from locating the problem within the student in terms of his or her individual abilities and attributes, to a focus on educational factors such as course design and assessment practices that may hinder or facilitate student engagement (Hathaway, 2015). Recently, an edited collection of articles on writing centre development in South Africa has showcased a range of models and approaches for promoting writing development in and across disciplines (Clarence \& Dison, 2017). However, this scholarly approach within higher education studies does not always inform practice, and many institutions continue to develop and offer student 'support' programmes that focus on individual students and their perceived deficits. Scott (2017), in a series of articles in the Mail and Guardian on obstacles to access and success in higher education, attributes the persistence of high dropout and failure rates to the absence of systemic curriculum and pedagogical development. He recognises the crucial role of the 'sustained development of academic literacies' for successful learning, but argues that 'current mainstream programmes make little or no provision for their development as an integral part of the curriculum'.

In this paper, we suggest that discipline-embedded writing centres have the potential to be part of a systemic approach to challenge and shift entrenched deficit practices in ways that are empowering to students and that strengthen the discipline. Although discipline-specific approaches do not intrinsically counter deficit approaches, we argue that discipline-specific writing centres are well-positioned to assist in the transformative project so that students acquire valued discourse-specific literacy practices and develop a stronger sense of self and place in the academy. We suggest that universities could benefit from examining the extent to which deficit notions of students, unexamined hierarchies and entrenchment of generic writing development programmes perpetuate unequal access and compromise quality teaching and learning. Furthermore, we show that discipline-specific writing centres have the following potential: to facilitate dialogue between students, literacy practitioners and other academic staff; to develop student voice, to deepen discipline-specific curriculum and assessment conversations; and to contribute to disciplinary development and reflexivity. To support these claims, we draw on examples from two discipline-specific writing centres, which are based in the Schools of Law and Education at a South African university.

\section{WRITING DEVELOPMENT IN HIGHER EDUCATION IN SOUTH AFRICA}

It is important to revisit, briefly, the history of academic development in South Africa, in order to understand how this history has shaped the role of writing centres in South African universities. There is a fairly consistent argument in tracing this history (Boughey, 2010; McKenna, 2010; Scott, Yeld \& Hendry, 2007), which involves a shift away from 'blame the student' discourses of student support to an acknowledgement of the role of academic literacy as a social practice. The main focus in the 1980s and early 1990s was on the support programmes offered to 'educationally disadvantaged' students whose apartheid schooling had not prepared them for the cognitive and discourse demands of university study. During this time, the standard way of thinking about academic writing and literacy development work 
was remedial in nature. It aimed at bridging the gap between these students' prior schooling and the expectations of higher education literacies and learning.

The key shift in higher education between 1990 and 1999, in line with recognising relationships of discourse and power, was that academic development practitioners opted for 'a focus on curriculum and staff development rather than student disadvantage' (Thesen \& Van Pletzen, 2006: 6). The emergence of South African writing centres that occurred during this time to provide writing support for students did not, however, form part of this shift that Thesen and Van Pletzen (2006) describe. Instead, they tended to operate within the traditional writing centre model in which students received generic writing advice or feedback on essay drafts by consultants who were not always familiar with the disciplinary discourses or requirements. In fact, in an earlier book showcasing writing centres in South Africa, Archer and Richards (2011: 9) argue that the notion of writing centres as 'safe space(s), discrete from the harshness of academia, is to push writing centres (further) out of the centre of university activities'. In response to this pattern, our work draws on research in the field of 'writing in the disciplines' (Deane \& O’Neill, 2011; Ganobcsik-Williams, 2011; Skillen, 2006), which critiques the notion of writing as a homogenous practice that can be generalised to all academic contexts. We endorse the move towards contextualised models of writing development for all students, as illustrated in our examples in this article.

In the intervening 12 years since Hutchings' (2006) critical analysis of writing centres, the landscape has remained fairly unchanged. In South Africa today, despite some improvement in educational resources in South African primary and secondary schools since 1994, many students continue to come to university in a state of 'under-preparedness' (Boughey, 2010) and without the requisite thinking and writing discourses (Paxton \& Frith, 2016). Despite the literature showing that these students are best supported in the disciplines, funding tends to favour discrete projects that support students 'at risk' of failing. It therefore feels as if we have come full circle in our attempts to embed writing practices in the disciplines. There is evidence of building writing practices systematically into curricula (McKay \& Simpson, 2013), such as the roll-out of writing intensive courses in which lecturers develop writing activities to develop critical thinking in the discipline (Nichols, 2017). Gottlieb and Greenbaum (2018: 57) show that, by integrating a legal writing course into two first-year modules, students' writing, and their perceptions of learning, improved. However, systemic integrated writing programmes for all students which facilitate meaning-making in unfamiliar discourses have not taken root as a widespread institutional practice, and writing development at universities is still mostly set apart from the mainstream curricula.

We argue that, in order to contribute more meaningfully to institutional and student development, writing centres should 'be incorporated into disciplinary practices' (Hutchings, 2006: 13), rather than being extra-departmental. The transformative space that we propose not only serves to transform students' experience of writing development, but also changes the relationships between students and the academy and between disciplinary specialists and writing centres, as well as changing the institution's overall approach to writing and curriculum development. It includes making explicit what is valued about the underlying discipline, how it is assessed, and which evaluative criteria are of significance.

\section{ACADEMIC LITERACIES AND TRANSFORMATIVE WRITING PEDAGOGY}

We work, like many other South African universities, from a broadly academic literacies perspective, finding particular resonance with Lillis and Scott's (2007) position that academic

Per Linguam 2019 35(1):1-14

http://dx.doi.org/10.5785/35-1-851 
literacies research is explicitly transformative rather than normative. Part of this notion of being transformative, they argue, is to challenge the educational myths described by Kress (2007: 22-23): that there is a homogenous student population that is inducted into stable and static disciplines, in contexts where the teacher-student relationship is unidirectional. These myths seem particularly fictional to all working in higher education in South Africa at this time. Our student population is diverse in terms of language, culture, race, class and education. Knowledge systems and institutions are being challenged amidst calls for a less Eurocentric curriculum, and students are demanding a less hierarchical relationship between the academy and the student body (Booysen, 2016). Although current questions of transformation in a South African context draw on a different theoretical and historical context, we argue that this 'ideological model of literacy' (Lea \& Street, 1998) offers a way of thinking about transforming academic writing development in a way that is both socially responsive and theoretically coherent. We echo Boughey and McKenna's (2016: 7) argument that we 'have to find ways of supporting those engaged in making the powerful knowledge promised by the university accessible to all who enter' and suggest that a collaborative pedagogy can facilitate this.

An academic literacies perspective understands language and writing as discourse, or social practice (Fairclough, 1995), rather than as an autonomous set of skills, and so rejects the assumption that 'linguistic issues can be successfully dealt with outside the mainstream lecture hall "home" discipline, either by the academic development person located within the specific discipline but nevertheless something of an "outsider" or worse, by a completely separate and decontextualised course' (Clarence, 2010: 18). Clarence (2010: 19) observes further that there are three major implications of this understanding:

- that texts need to be read and produced in discipline-specific contexts;

- that texts in different disciplines are underpinned by different values, assumptions and patterns, which lead to different surface features; and

- that, most importantly, the specific features of new, discipline-specific texts will not be recognised (or produced) without explicit instruction and induction into the disciplinary discourse.

These implications are congruent with Northedge's (2003: 175) argument that the key role of the teacher is to 'coach' students so that they can speak and write the discourse competently and use appropriate 'terms, concepts and modes of argument'. However, a transformative approach extends this role, so that these norms can be critiqued and re-examined (Lillis \& Scott, 2007). Thus, an academic literacies approach to writing development is not only deeply embedded in the discipline, but also requires a critical engagement with writing norms. This happens through explicit discussion, where the values, assumptions and patterns underlying texts can be made more visible and students are empowered to negotiate identity and voice within discoursal communities (Hathaway, 2015).

Gourlay (2009) argues that such academic literacies are threshold practices, as they allow students to consolidate their identities within the university community and become familiar with how academic literacy works within the discourse. As suggested earlier, a powerful way of engaging in such threshold practices is through Jacobs' (2007, 2016) 'collaborative pedagogy'. This collaboration, in which subject specialists and writing specialists jointly plan and facilitate the teaching and assessment of writing assignments, is distinct from cooperation, in which the writing specialist may draw on content-specific texts, but is solely responsible for all writing development activities (Wingate, 2011). Collaborative pedagogy is Per Linguam 2019 35(1):1-14 http://dx.doi.org/10.5785/35-1-851 
congruent with Deane and O'Neill's (2011: 7) work Writing in the disciplines, particularly their argument that teaching powerful forms of writing in the disciplines does not necessarily imply that one is uncritical, or complicit in silencing alternative voices or practices. Having an 'outsider' interrogate accepted practices - and having an 'insider' to explain, defend or further critique them - allows for the creation of spaces where different voices, positions and values can be shared and heard.

In this regard, we work, particularly, with Lillis' (2011) concept of dialogue as process. She suggests that some of the goals of pedagogic dialogue are 'to familiarise student-writers with the conventions of academia; to generate opportunities and possibilities for contestations and challenge; and to make language visible in text and knowledge-making' (Lillis, 2011: 408). Dialogue, then, not only facilitates critical engagement with writing and language norms, but allows students to become active participants in the construction and deconstruction of texts, as well as giving them more of a voice as they become part of the disciplinary community.

\section{DISCIPLINE-BASED WRITING CENTRES AND THEIR POTENTIAL FOR TRANSFORMATION}

With Hathaway (2015: 507), we suggest that 'all students, whatever their linguistic identities, can benefit from an explicit and structured introduction to academic writing' and that 'this tuition should no longer be seen as support, and therefore marginalised, but as a transformative process of acculturation that needs to be located in the mainstream of the university'. This echoes Harrington's (2016: 13) belief that 'the normative has the potential to enable the transformative'. Her description of the transformative power of the academic literacies approach in creating or delineating 'living, creative yet protected spaces' (Harrington, 2016: 13) is a powerful one that we are attempting to embody in the Schools of Education and Law.

The writing centres both draw on some core working principles and have observed five conditions under which student engagement with the discourses is enabled. Firstly, they work primarily with all students, and with mainstream curriculum writing tasks, rather than focusing exclusively on 'under-prepared' or 'struggling' students, or additional writing development tasks. Secondly, both draw on Jacobs' $(2007,2016)$ collaborative pedagogy, in which materials development and task design with lecturers are valued over the provision of generic writing solutions offered by the academic literacy practitioner. Through this collaboration, possibilities are created for influencing and improving the quality of course assessment and marking practices, and for facilitating epistemological access to core course concepts. Thirdly, trained peer writing consultants play a critical role, in that they are both insiders and outsiders themselves. They are successful student-writers, from the same discipline as the students, who have the ability to unpack, explain and critique discoursal writing conventions, while remaining outside of the traditional hierarchies of power in the academy with its summative assessment and measurement imperatives. This means that they are more aware of their impact on student experience. Fourthly, the capacity to reflect and engage in dialogue, with staff and students, are two consistently used strategies. Both students and peer consultants are encouraged to engage in ongoing reflection on their writing strengths and difficulties. There is also dialogue between academic staff and peer consultants, so that these consultants provide feedback to staff - both literacy and disciplinary specialists - about the writing assignment's challenges, limitations or opportunities for learning. This reflects a significant shift from the more traditional role, where peer consultants had little communication with disciplinary specialists, and the consultants' work was to make explicit

Per Linguam 2019 35(1):1-14

http://dx.doi.org/10.5785/35-1-851 
the writing demands of the task, or discipline, to students. Finally, institutional culture is positively affected by this focus on student engagement and learning, rather than on throughput statistics and quantitative measurement.

We now turn to some practical examples, to illustrate these conditions in context:

\section{Participants: From 'at risk' students to all students}

The writing centre located at the School of Education has begun to implement a more integrated and proactive approach to embedding the writing development for all first-year education students: a programme originally established for students deemed 'at risk' of failure has been extended to include all students. In 2015, students who had underperformed in a diagnostic benchmark test were required to attend a small group session (maximum of six per group) on a weekly basis with an assigned writing consultant at the writing centre. The purpose of these materials-based sessions was to interrogate what particular assignment tasks were asking students to do; to consolidate students' active and critical engagement with the course texts; and to make explicit the conceptual and writing requirements for Education Studies, a compulsory first-year theoretical course. This approach relied on a writing specialist using subject-specific texts and tasks as a basis for designing contextualised writing activities, and involved some collaboration with course lecturers to design the writing activities. After the perceived success of this intervention for this cohort of 'weaker' students, which was reflected in the improved results in essays and examinations of the students who attended regularly, the School of Education has opened up the intervention to all first-year students by using the Education Studies curriculum as a basis for developing learning materials.

In 2015, the School of Law's writing centre piloted an embedded spiral writing curriculum as part of the four-year LLB programme. The foundational first-year course, Introduction to Law, has three weeks of teaching time dedicated to writing development. In this way, all firstyear law students engage with the explicated discourse demands of legal writing, and academic writing in law. In subsequent years, different courses have smaller spaces dedicated to the teaching of or engagement with different aspects of legal writing. For example, in Criminal Law, a double lecture is dedicated to a detailed task analysis and modelling of the kind of legal argument required in its main assignment. In Jurisprudence, a pre-assignment workshop on writing using social theory is held, followed by a post-assignment, preexamination workshop, in which writing, drawing on multiple critical perspectives, is offered. These lectures, workshops and tutorials are presented to students as part of the core curriculum: set out in course outlines; discussed in lectures; and generally taught in the usual venue for that course. In these ways, writing development is reconceptualised as a necessary part of all law students' induction into the discourse, rather than the teaching of a set of skills to 'at-risk' students.

\section{Collaborative pedagogy and its impact on course design}

A major benefit of the education writing centre intervention has been to involve the Education Studies lecturers and tutors more centrally in students' reading and writing development. Many of these lecturers and tutors had previously regarded students' writing problems as outside of their domain and did not have a specific interest in promoting students' academic literacy in their courses. The process of working with lecturers collaboratively (Jacobs, 2007; Wingate, 2011) in designing tutorial activities and clarifying assignment criteria and standards

Per Linguam 2019 35(1):1-14

http://dx.doi.org/10.5785/35-1-851 
has created a transformative space for raising lecturers' awareness about the possibilities for writing development in the discipline. As they had to explain their criteria explicitly to students in writing workshops, the lecturers began to re-examine their assessment questions and draw on sound 'assessment for learning' principles to formulate clearer assessment criteria and develop 'learning oriented' rubrics (Carless, 2015).

A consequence of this collaboration is that mainstream tutorials ${ }^{\mathrm{i}}$ have become the locus for embedded writing development. Regular planning meetings occur between the writing centre writing specialists and discipline specialists to co-design these 'reading and writing to learn' activities for use in the tutorials. There is an increased emphasis on pedagogical strategies for concept mapping and vocabulary development using the course texts and assessment tasks rather than relying on tutorial dialogues in which only a few students (who have read the texts) will participate. Exemplars of student writing are jointly analysed in tutorials to familiarise students with the good quality analysis and arguments expected of them (Carless, 2015).

What started out as an intervention for 'at risk' students, situated firmly in the deficit perspective, has evolved into a more deliberate writing programme in which students' disciplinary thinking develops through writing activities. Subject specialists see the importance of developing students' academic writing by collaborating with writing specialists to create a culture of learning that advances all students. This has implications for changing lecturers' specialist identities as they 'move out of the comfort zones of teaching what (they) have been taught' (Boughey \& McKenna, 2016: 7) to finding ways of making the literacy expectations transparent and accessible.

Similarly, at the School of Law, collaboration between the literacy specialist and disciplinary specialists occurs at the levels of planning, materials development and teaching. In the Introduction to Law example, mentioned above, materials and lectures are co-designed, and the lecture time is co-facilitated by writing centre staff and the Introduction to Law lecturers. An engagement with a second-year, content-heavy course further illustrates this principle: although lawyers have to work, draft and write in teams for much of their professional lives, writing assignments in our law school remain largely individual tasks. The Delict course coordinator was eager to explore a principled way of getting students to write collaboratively. We developed a highly scaffolded and explicated group assignment that was facilitated through a series of writing tutorials. As with the Education Studies example, it was supported by a detailed rubric that set out both the rationale and criteria for the work. This assignment was the main form of assessment for the semester. Both the assignment topic and the rubric were developed through a series of conversations between disciplinary specialists and the writing centre staff.

The framing of the assignment as necessary and empowering work to equip students for legal practice helped most students to accept that writing together was professionally necessary, rather than an added burden. The fact that this conversation was facilitated by the Delict lecturer - who had experience in a corporate law firm - gave this assignment a validity that it would not have had if it was simply offered as a simulation by the writing centre. The tutorials and rubric were designed jointly by the writing centre staff and the Delict lecturer, which also helped to position this assignment at the core of the course. Secondly, the students experienced the assignment at the heart of their course, because it drew on core delictual 
principles. The assignment was also given more gravitas through mediation by experts in Delict, rather than by an 'outsider'. This illustrates our claim that embedded writing develop strengthens epistemological access (Morrow, 2007) to both content and writing.

\section{Peer writing consultants as 'insiders'}

The redesigned tutorial programme in education studies has given rise to a number of structural and pedagogical changes, where the writing consultants have been assigned a new role in assisting students to write purposively in the tutorials using the contextualised tutorial materials. Consequently, the training of writing consultants has become more tailored to their newly acquired roles as facilitators within a formal teaching context. These writing consultants also assist in facilitating compulsory writing workshops attended by several hundred students and run jointly by the writing centre coordinator and course lecturers. Writing workshops clarify for the education studies students what is expected of them in the assessment tasks, and in so doing, 'model the discourse of the discipline in action, for enabling students to learn how to use this discourse and become members of the disciplinary community themselves' (Harrington, 2011: 57-58). All of the above is made possible because the writing consultants are themselves education students and therefore part of the disciplinary community.

Similarly, appointing 10 law students as writing consultants and training them in writing development pedagogy is one of the conditions for success at the School of Law's writing centre. The students, as 'insiders' to the discourse, are able to appreciate the differences between an academic argument in law, and an academic argument in another discipline, as they all have had to shift their writing practices between law and other subjects. By equipping them with a shared language to make some of these differences and requirements explicit, these student consultants are able to make discourse demands visible to fellow students, both in face-to-face consultations and in formative feedback on draft assignments. However, drawing on their own experience of being inducted into the discipline, these consultants are also able to facilitate and participate in critical conversations about these norms and the power relations that they implicitly uphold. In this way, we see consultations shifting between the normative and the transformative.

\section{Dialogue and reflection as tools for transformation}

Working within the disciplines creates opportunities for regular reflection on learning and writing development, and for dialogue about the learning and writing process. This occurs among students, consultants and academics.

In law, the Introduction to Law lecturer and the writing centre lecturer draw predominantly on Lillis' notion of the centrality of dialogue in an academic literacies pedagogy (in GanobcsikWilliams, 2006). Material is presented through conversation and critique, rather than as a truth that must be learned. For example, in a recent class focusing on legal research, the lecturers presented a brief overview of common principles, and then interrogated them. The two lecturers interviewed each other in front of the class about their approach to research, and took turns to point out how this was similar or different to the common principles. In these conversations, difference and nuance were valued. Students were invited to become involved in the conversations, and to share their concerns, questions, strategies and frustrations about the research and writing processes. Another example of reflection and dialogue in law occurs during and after each round of draft review of first-year assignments. Consultants and writing 
centre staff share core insights and concerns about the writing in process with disciplinary specialists and students, in the form of a written reflection sheet. Students (who have read the sheet before class) interrogate the feedback, get clarity, and express any ongoing frustrations or concerns they may have regarding the assignment or draft review process.

In education, the writing consultants draw on 'changing conceptions of feedback' (Boud \& Malloy, 2013: 3) and reflective forms of writing to structure students' critical engagement with the feedback on their essays. In pairs or groups, students discuss the nature of the feedback and how best to address core conceptual, structural and language challenges. This shifts the focus away from an exclusive mark or results orientation to one in which students learn strategies and take ownership of their writing. It also models good practice for students as future teachers.

\section{CONCLUSION}

Traditionally, writing centres have relied on students to take the initiative and to use available resources if they believed they were struggling in particular areas of academic literacy. Our argument in this paper is to counter this approach and prevailing university views that the problem lies with the students who lack the requisite academic literacy skills. We have attempted to create spaces in the curriculum in which all students, disciplinary specialists and writing centre staff work collaboratively and dialogically over a sustained period of time on written assignments. This approach, as shown by the examples in this article, not only removes the pressure on students to 'seek help', it creates a less hierarchical space in which all writers in the discourse community are seen to benefit from writing conversations and engagements based on course concepts and assignments. We have shown the conditions of possibility for systematically integrating writing development into these courses.

There are questions that require further investigation. Further evaluation of the programmes is needed to assess the extent to which students have understood the discourse requirements and felt able to critique them. We would like to find ways of involving our students more in the identification of key issues and sites of struggle for critique and discussion. We also need to find out more about the extent to which there is an entrenched and nuanced understanding of this approach within each of our disciplines. Without this, the programmes are only as strong as the individuals running them, and they run the risk of reverting to the stand-alone generic skills approach in their absence.

That said, it is worth reiterating the principles that have guided our attempts to create transformative writing spaces in university curricula. Firstly, there must be an explicit rejection of the deficit position - writing development work should be reframed as being valuable for all students. This is opposed to writing development being seen as an add-on for alternate access students, or a pre-university entrance requirement, or an extra, optional course. Secondly, writing development should occur within specific disciplinary discourses, and be systematic, curriculated and less ad hoc. A transformative writing space depends on strong non-hierarchical relationships between disciplinary specialists, writing centres and students. Thirdly, collaborative pedagogy, dialogue and reflection are useful concepts to inform writing development work because they encourage a dynamic process which is responsive to the needs of both students and the academy. Finally, we reiterate that academic literacies and the content of the disciplines can and should be reconceptualised and taught to facilitate and deepen epistemological access (Morrow, 2007) for all students. 


\section{REFERENCES}

ADAM, F, J BACKHOUSE, J BALOYI \& T BARNES. 2010. Access and throughput in South African higher education: three case studies. Pretoria: Council on Higher Education.

ARCHER, A \& R RICHARDS. 2011. Changing spaces: writing centres and access to higher education. Stellenbosch: African Sun Media.

ASHWIN, P, D BOUD, K COATE, F HALLET, E KEANE, K KRAUSE \& B LEIBOWITZ. 2015. Reflective teaching in higher education. London: Bloomsbury.

BIGGS, J \& C TANG. 2011. Teaching for quality learning at university. London: The Society for Research into Higher Education.

BITZER, E. 2009. Higher education in South Africa: a scholarly look behind the scenes. Stellenbosch: African Sun Media.

BOOYSEN, S (Ed.). 2016. Fees must fall: student revolt, decolonisation and governance in South Africa. Johannesburg: Wits University Press.

BOUD, D \& E MALLOY. 2013. What is the problem with feedback? In D Boud \& E Malloy (Eds), Feedback in higher and professional education. London: Routledge. 1-11.

BOUGHEY, C. 2010. Understanding teaching and learning at foundation level: a 'critical' imperative. In C Hutchings \& J Garraway (Eds), Beyond the university gates: provision of extended curriculum programmes in South Africa. Cape Town: Cape Peninsula University of Technology. 4-7.

BOUGHEY, C \& S MCKENNA. 2016. Academic literacy and the decontextualized learner. CriSTaL, 4(2):1-9.

CARLESS, D. 2015. Excellence in university assessment: learning from award-winning practice. London: Routledge.

CLARENCE, J. 2010. Academic development and the 'language problem'. In C Hutchings \& J Garraway (Eds), Beyond the university gates: provision of extended curriculum programmes in South Africa. Cape Town: Cape Peninsula University of Technology. 16-20.

CLARENCE, S. 2018. Understanding student experiences through the lens of academic staff development practice and research. In P Ashwin \& J Case (Eds), Higher education pathways: South African undergraduate education and the public good. Cape Town: African Minds. 204-215.

CLARENCE, S \& L DISON (Eds). 2017. Writing centres in higher education: working in and across the disciplines. Stellenbosch: Sun Press.

CROSS, M, Y SHALEM, J BACKHOUSE \& F ADAM. 2009. How undergraduate students negotiate academic performance within a diverse university environment. South African Journal of Higher Education, 23(1):21-42.

DEANE, M \& P O'NEILL (Eds). 2011. Writing in the disciplines. Hampshire: Palgrave Macmillan.

FAIRCLOUGH, N. 1995. Critical discourse: the critical study of language. London: Longman.

GANOBCSIK-WILLIAMS, L (Ed). 2006. Teaching academic writing in UK higher education: theories, practices and models. Hampshire: Palgrave Macmillan.

GOTTLIEB, T \& L GREENBAUM. 2018. The effect of integration on learning: an analysis and evaluation of a legal writing project in a South African Law Faculty. Per Linguam, 34(1):47-59.

GOURLAY, L. 2009. Threshold practices: becoming a student through academic literacies. London Review of Education, 7(2):181-192.

Per Linguam 2019 35(1):1-14

http://dx.doi.org/10.5785/35-1-851 
HARRINGTON, K. 2010. The role of assessment. In M Deane \& P O’Neill (Eds), Writing in the disciplines. Hampshire: Palgrave Macmillan. 48-64.

HATHAWAY, J. 2015. Developing that voice: locating academic writing tuition in the mainstream of higher education. Teaching in Higher Education, 20(5):506-517.

HUTCHINGS, C. 2006. Reaching students: lessons from a writing centre. Higher Education Research and Development, 25(3):247-261.

HUTCHINGS, C \& J GARRAWAY. 2010. Beyond the university gates: provision of extended curriculum programmes in South Africa. Cape Town: Cape Peninsula University of Technology.

JACOBS, C. 2007. Mainstreaming academic literacy teaching: implications for how academic development understands its work in higher education. South African Journal of Higher Education, 21(7):870-881.

JACOBS, C. 2016. Opening up the curriculum: moving to the transformative in teachers' understanding of disciplinary literacy practices. In T Lillis, K Harrington, M Lea \& $\mathrm{S}$ Mitchell (Eds), Working with academic literacies: case studies towards transformative practice. Colorado: The WAC Clearinghouse/Parlor Press. 131-142.

JOSEPH, N. 2016. What final exam results reveal about South Africa's school system. Available from https://theconversation.com/what-final-exam-results-reveal-about-southafricas-school-system-52780 [Accessed: 15 May 2017].

KRESS, G. 2007. Thinking about meaning and learning in a world of instability and multiplicity. Pedagogies: An International Journal, 1:19-34.

LEA, MR \& B STREET. 1998. Student writing in higher education: an academic literacies approach. Studies in Higher Education, 23(2):157-172.

LILLIS, T \& M SCOTT. 2007. Defining academic literacies research: issues of epistemology, ideology and strategy. Journal of Applied Linguistics, 4(1):5-32.

LILLIS, T. 2011. Legitimizing dialogue as textual and ideological goal in academic writing for assessment and publication. Arts and Humanities in Higher Education, 10(4):401432.

LILLIS, T, K HARRINGTON, M LEA \& S MITCHELL. 2016. Working with academic literacies: case studies towards transformative practice. Colorado: The WAC Clearinghouse/Parlor Press.

MACVAUGH, J, A JONES \& S AUTY. 2014. Implicit, stand-alone or integrated skills education for undergraduates: a longitudinal analysis of programme outcomes. Journal of Further and Higher Education, 38(6):755-772.

MANN, S. 2001. Alternative perspectives on the student experience: alienation and engagement. Studies in Higher Education, 26(1):7-19.

MCKAY, T \& Z SIMPSON. 2013. The space between: collaboration between a writing centre and an academic department. Perspectives in Education, 31(4):27-42.

MCKENNA, S. 2010. Cracking the code of academic literacy: an ideological task. In C Hutchings \& J Garraway (Eds), Beyond the university gates: provision of extended curriculum programmes in South Africa. Cape Town: Cape Peninsula University of Technology. 8-15.

MITCHELL, S \& A EVISON. 2006. Exploiting the potential of writing for educational change at Queen Mary, University of London. In L Ganobcsik-Williams (Ed.), Teaching academic writing in UK higher education: theories, practices and models. Hampshire: Palgrave Macmillan. 68-84.

MBEMBE, A. 2016. Decolonizing knowledge and the question of the archive. Keynote address (3) at the International Conference of Educational Development, Cape Town,

Per Linguam 2019 35(1):1-14

http://dx.doi.org/10.5785/35-1-851 
24 November. Available from http://heltasa.org.za/heltasaiced-conference-2016 [Accessed: 16 June 2017].

MITCHELL, S \& A EVISON. 2006. Exploiting the potential of writing for educational change at Queen Mary, University of London. In L Ganobcsik-Williams (Ed.), Teaching academic writing in UK higher education: theories, practices and models. Hampshire: Palgrave Macmillan. 140-153.

MORRELL, R. 2016. Op-Ed: teaching in a time of protest. Available from https://www.dailymaverick.co.za/article/2016-10-05 [Accessed: 5 November 2016].

MORROW, W. 2007. Learning to teach in South Africa. Cape Town: HSRC Press.

NICHOLS, P. 2017. Writing democracy. In Clarence, S \& L Dison (Eds), Writing centres in higher education: working in and across the disciplines. Stellenbosch: Sun Press. 3547.

NORTHEDGE, A. 2003. Enabling participation in academic discourse. Teaching in Higher Education, 8(2):169-180.

PAXTON, M \& V FRITH. 2016. Transformative and normative? Implications for academic literacies research in quantitative disciplines. In $\mathrm{T}$ Lillis, $\mathrm{K}$ Harrington, $\mathrm{M}$ Lea \& $\mathrm{S}$ Mitchell (Eds), Working with academic literacies: case studies towards transformative practice. Colorado: The WAC Clearinghouse/Parlor Press. 155-162.

SCOTT, I, N YELD \& J HENDRY (Eds). 2007. Higher education monitor: a case for improving teaching and learning in South African higher education (Vol. 6). Pretoria: Council of Higher Education.

SCOTT, I. 2017. Core issues besides finance and access hinder students' success. Available from https://mg.co.za/article/2017-10-20-00-core-issues-besides-finance-and-accesshinder-students-success [Accessed: 2 April 2019].

SKILLEN, J. 2006. Teaching academic writing from the 'centre' in Australian universities. In L Ganobcsik-Williams (Ed.), Teaching academic writing in UK higher education: theories, practices and models. Hampshire: Palgrave Macmillan. 140-153.

THESEN, L \& E VAN PLETZEN. 2006. Academic literacies and languages of change. London: Continuum.

WINGATE, U. 2007. A framework for transition: supporting 'learning to learn' in higher education. Higher Education Quarterly, 61(3):391-405.

WINGATE, U. 2011. A comparison of 'additional' and 'embedded' approaches to teaching writing in the disciplines. In M Deane \& P O'Neill (Eds), Writing in the disciplines. Hampshire: Palgrave Macmillan. 65-87.

WINGATE, U \& C TRIBBLE. 2012. The best of both worlds? Towards an English for academic purposes/academic literacies writing pedagogy. Studies in Higher Education, 37(4):481-495. 


\section{BIOGRAPHICAL NOTES}

Laura Dison is a teaching, learning and assessment specialist in higher education and is the academic head of the Wits School of Education Writing Centre. She is the programme coordinator of the Wits Postgraduate Diploma in Higher Education. 1aura.dison@ wits.ac.za

Jean Moore is a language and writing development specialist. Her doctoral research focuses on conceptions of legal knowledge and their impact on legal writing. She co-directs the work of the Wits School of Law Writing Centre. jean.moore@wits.ac.za

\section{END NOTES}

' Tutorials are a compulsory teaching activity at the School of Education for students to consolidate their understanding of course theories and concepts in smaller groups (of about 40) that meet once a week for two hours. 